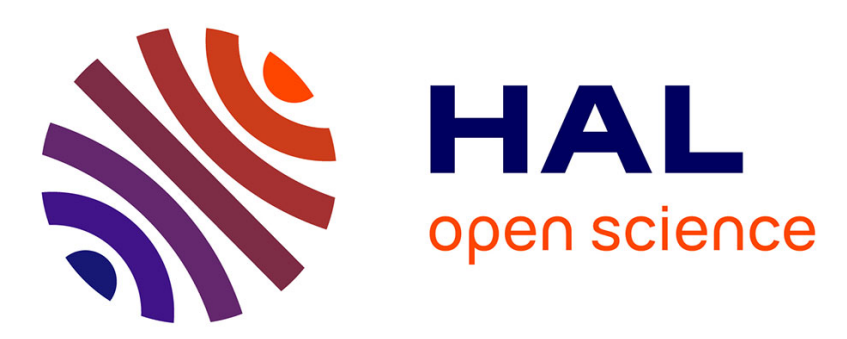

\title{
Study on cervical muscle volume by means of three-dimensional reconstruction
}

Fan Li, Aurélien Laville, Dominique Bonneau, Sébastien Laporte, Wafa Skalli

\section{To cite this version:}

Fan Li, Aurélien Laville, Dominique Bonneau, Sébastien Laporte, Wafa Skalli. Study on cervical muscle volume by means of three-dimensional reconstruction. Journal of Magnetic Resonance Imaging, 2013, 39 (6), pp.1411-1416. 10.1002/jmri.24326 . hal-03219773

\section{HAL Id: hal-03219773 \\ https://hal.science/hal-03219773}

Submitted on 6 May 2021

HAL is a multi-disciplinary open access archive for the deposit and dissemination of scientific research documents, whether they are published or not. The documents may come from teaching and research institutions in France or abroad, or from public or private research centers.
L'archive ouverte pluridisciplinaire HAL, est destinée au dépôt et à la diffusion de documents scientifiques de niveau recherche, publiés ou non, émanant des établissements d'enseignement et de recherche français ou étrangers, des laboratoires publics ou privés. 


\title{
Study on Cervical Muscle Volume by Means of Three-Dimensional Reconstruction
}

\author{
Fan Li, PhD, ${ }^{1,2 *}$ Aurélien Laville, $\mathrm{PhD},{ }^{1}$ Dominique Bonneau, MD, PhD, ${ }^{1}$ \\ Sébastien Laporte, $\mathrm{PhD},{ }^{1}$ and Wafa Skalli, $\mathrm{PhD}^{1}$
}

Purpose: To quantify the cervical muscle volume variation by means of three-dimensional reconstruction from MRI images.

Materials and Methods: Sixteen subjects were scanned using a Philips MRI scanner, including 11 men and 5 women, aged from 23 to 33 years, weighting between 49$80 \mathrm{~kg}$. The deformation of a parametric specific object method was used to develop three-dimensional muscle models from contours on a small number of MRI images. Six subjects were reconstructed by two observers for evaluating the reliability by means of intraclass correlation coefficient (ICC). The results were also compared with in vivo measurement on a single specimen from a reference literature. The difference in left and right muscles volumes was assessed with a paired Wilcoxon signed rank test.

Results: The results showed good reliability by means of ICC study and were consistent with the in vivo specimen measurements. The left and right paired muscle volumes showed no significant difference. Interindividual variance was large that could reach $364 \mathrm{~cm}^{3}$, but the ratio of a given muscle volume to the total volume was less variable, always lower than $13 \%$. The maximum cross sectional areas of cervical muscles varied greatly between individuals and the maximum values were mostly found at the C6-C7 level.

Conclusion: This study provides initial results which could be used as reference data for clinical evaluation and biomechanical model development.

Key Words: cervical muscle; muscle volume; MRI reconstruction; clinical evaluation; biomechanics

\footnotetext{
${ }^{1}$ Arts et Métiers ParisTech, LBM, Paris, France.

${ }^{2}$ State Key Laboratory of Advanced Design and Manufacture for Vehicle Body, Hunan University, Changsha, People's Republic of China.

Contract grant sponsor: National Natural Science Foundation of China; Contract grant number: 51205117; Contract grant sponsor: Fondation Franco-Chinoise pour la Science et ses Applications; Contract grant sponsor: Chinese Scholarship Concile; Contract grant sponsor: BiomecAM Chair Program.

*Address reprint requests to: F.L., Office 327, College of Mechanical and Vehicle Engineering, Hunan University, Changsha 410082 China. E-mail: lifandudu@163.com
}

DOI $10.1002 / j m r i .24326$
THE VOLUME OF a muscle determines the maximal muscle force it can generate, and reductions in cervical muscle volume may result in neck pain and even reduction in proprioceptive sensitivity (1-4). Biomechanical studies on cervical muscle today have focused on the cross-sectional area (CSA) and moment arm characteristics to evaluate the force and moment generating capacity of the human cervical muscle system $(2,3,5)$. However, this kind of data does not represent the entire muscle interindividual variability. Moreover, in clinical evaluation, muscle volume evolution cannot be measured directly from the CSA data and in vivo volume measurement is still technically challenging. To quantify the ranges and the proportions of cervical muscles can help clinical diagnosis on physiological abnormal muscle system or single muscle problem. On the other hand, although Finite Element (FE) head-neck models have been widely applied for biomechanical studies $(6,7)$, accounting for interindividual variability is still an issue.

There are two main approaches for assessing muscle volume, cadaver measurement and reconstruction from medical imaging $(8,9)$. But due to the limited availability of cadaveric specimens, tedious dissection process and qualitative processing, there is few dissection studies related to cervical muscle volume study. In contrast the application of the latter medical imaging approach is more extensive because of the possibility to obtain measurements on a range of living subjects. However, up to now only one study investigated neck muscle volume in 17 subjects from MRI data (8). Normally to reconstruct three-dimensional geometry of neck musculature, muscle contours on each slice needed to be outlined manually, but recently a DPSO (deformation of a parametric specific object) method proposed by Jolivet et al $(10,11)$ has been developed to generate three-dimensional (3D) muscle models from a small number of axial images enabling quantitative analysis of muscle volume in a large number of subjects.

The aim of the present study is to investigate the cervical muscle variation by means of $3 \mathrm{D}$ reconstruction from MRI images using the DPSO method. 


\section{MATERIAL AND METHODS}

\section{Subjects}

Sixteen healthy volunteers (11 men and 5 women) without history of neck illness were included in the present study (age $28 \pm 4$ years; range, 23-33 years; weight $68.1 \pm 9.6 \mathrm{~kg}$; range, $49-80 \mathrm{~kg}$ ). The protocol was approved by the ethical committee of our institution (CPP-06036) and all subjects gave their informed written consent before participation in the examination according to the protocol.

\section{MRI}

A 1.5 Tesla (T) Philips MRI scanner was used to capture axial and sagittal images with two parts, one (thorax part) from T5 to C7 and the other (neck part) from $\mathrm{T} 1$ to basis crania. The basic parameters for all series included sequence $=\mathrm{SE}$, repetition time $(\mathrm{TR})=$ $4640 \mathrm{~ms}$, echo tim e(TE) $=40 \mathrm{~ms}$, slice thickness $=2$ $\mathrm{mm}$, space $=2.2 \mathrm{~mm}$, matrix size (axial plan) $=1024$ $\times 1024$ pixel, matrix size (sagittal plan) $=512$ pixel $\times$ 512 pixel, field of view of axial plan (neck parts) = $0.25 \mathrm{~m} \times 0.25 \mathrm{~m}$, field of view of axial plan (thorax parts) $=0.44 \mathrm{~m} \times 0.44 \mathrm{~m}$, field of view of sagittal plan $=0.49 \mathrm{~m} \times 0.49 \mathrm{~m}$.

\section{Muscle Volume Reconstruction}

The cervical muscles were divided into different groups (12), including sternocleidomastoid, trapezius, splenius (capitis and cervicis), longissimus (capitis and cervicis), semi spinalis capitis, transverse spinalis (semispinalis cervicis, multifidi and rotatores), ventral muscles (longus capitis and colli), scalenus (anterior, medius, and posterior), levator scapulae, rhomboid minor and hyoid muscles (suprahyoid and infrahyoid), based on the location and the function of the muscles (Fig. 1).

The DPSO (deformation of a parametric specific object) method proposed by Jolivet et al $(10,11)$ was applied for the reconstruction of three-dimensional cervical muscles by means of MRI data. The reconstruction process included three steps. First, contours of each muscle were outlined manually (Fig. 1) with a reduced number of slices (every 6 to 10 slices). Within suddenly shape change of a muscle, additional contours were outlined. Then, the other contours of all the slices were generated automatically by an interpolation

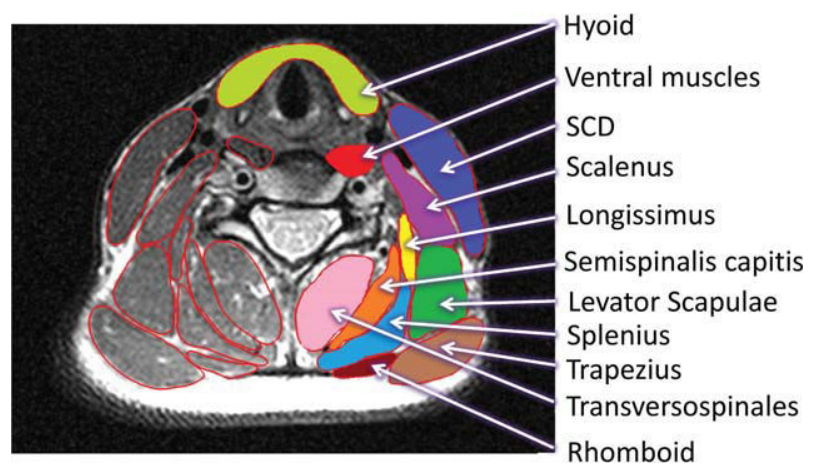

Figure 1. Definition of cervical muscle groups.

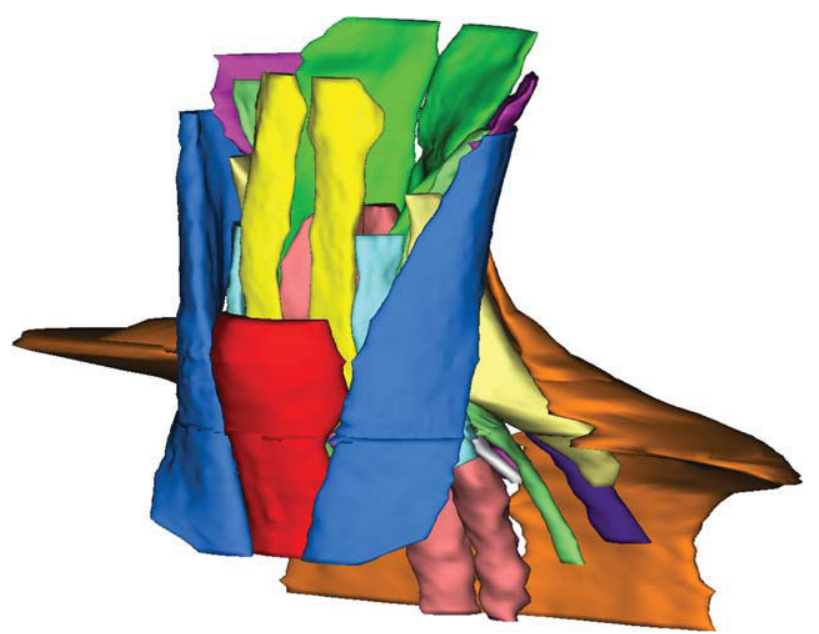

Figure 2. Geometry of cervical muscles.

of the existing contours and the approximate object obtained were deformed to fit the exact muscle contours on the images. The last step was a quick check of all the contours, and manual modifications were implemented when there were interpolation errors.

After the reconstruction, the two series of MRI images were merged to get the muscle models. Finally, all the cervical muscle volume geometries were obtained and muscle volumes were computed. The maximum cross sectional area of each muscle group in the axial plane was also calculated from the reconstruction.

\section{Reliability Evaluation}

To evaluate the reliability of the reconstruction, six subjects were reconstructed by two observers with a gap of one month and the muscle volume results were assessed with intraclass correlation coefficient (ICC) on the software SPSS. ICC3.1 (two-way mixed single measures, absolute agreement) was used for interobserver reliability evaluation, as defined by Shrout and Fleiss (13).

ICC reliability was considered slight $(0-0.2)$, fair (0.21-0.4), moderate (0.41-0.6), substantial (0.61$0.8)$, and excellent (0.81-1.0) for clinical application $(13,14)$. The mean difference and max difference of each muscle were also studied.

Additionally, the results of the six subjects were also compared with the in vivo measurement on the left side of a 50 th percentile specimen $(171 \mathrm{~cm}, 75 \mathrm{~kg})$ by Borst et al (9).

\section{Statistical Analysis}

Difference in left and right muscle volumes were assessed with a paired Wilcoxon signed rank test, where $P>0.05$ means no significant difference (15). The contribution of each muscle volume to total muscle volume was analyzed and the ratio was defined as:

$$
\text { Ratio }_{M_{i}}=\frac{V_{M i}}{V_{\text {total }}}
$$

where $M_{i}$ is the $i_{\text {th }}$ muscle, $V_{M i}$ is the volume of the $i_{\text {th }}$ muscle and $V_{\text {total }}$ is the total volume of cervical muscles. 


\section{RESULTS}

The geometry of cervical muscles from the reconstruction result was shown in Figure 2. The intraclass correlation coefficients $\left(\mathrm{ICC}_{3,1}\right)$ were all greater than 0.83 for muscle volume (Table 1), indicating very good reliability of the reconstruction method. The mean difference of the six reconstructions ranged from $0.9 \%$ to $6.4 \%$ and the maximal difference of each pair was less than $10 \%$ except the Hyoid muscle in one case where the difference was $11.6 \%$. The results were consistent with the in vivo specimen measurements (Fig. 3).

The left and right paired muscle volumes showed no significant difference under the Wilcoxon signed rank test, all the $P$ values were greater than 0.05 .

Trapezium occupied approximately $1 / 3$ of the total cervical muscle volume. Interindividual variance was large that could reach $364 \mathrm{~cm}^{3}$ (Fig. 4), but the ratio of a given muscle volume on the total volume was less variable, always lower than 13\%, as shown in Figure 5 and Table 2.

Great differences were found among individuals when measuring maximum muscle CSA in the axial plane (Fig. 6). Maximum CSA of trapezium was much larger than that of others, while the maximum CSAs of levator scapulae, hyoid, scalenus, sternocleidomastoid, transverso spinalis, semispinalis capitis, and splenius were more consistent. However, the locations of maximum CSAs were invariable among individuals in the present study (Table 3), and were found mostly in the $\mathrm{C} 6$ to $\mathrm{C} 7$ level while that of semi-spinalis capitis was found in $\mathrm{C} 1$ to $\mathrm{C} 2$ level. Other muscle groups including longissimus, ventral muscles and hyoid were found to be almost constant in CSA, and, therefore, the location of maximum CSAs occurred at a range of different levels.

\section{DISCUSSION}

The aim of this study was to quantify the cervical muscle volume variation by means of three-
Table 1

Results of Inter-observer Volume Reliability Study

\begin{tabular}{lccc}
\hline Muscle & ICC 3.1 & $\begin{array}{c}\text { Mean } \\
\text { difference }\end{array}$ & $\begin{array}{c}\text { Max } \\
\text { difference (\%) }\end{array}$ \\
\hline SCM R & 0.96 & 2.5 & 4.9 \\
SCM L & 0.98 & 2.1 & 4.4 \\
Trapezius R & 0.95 & 2.3 & 4.4 \\
Trapezius L & 0.89 & 3.8 & 7.0 \\
Splenius R & 0.98 & 1.6 & 3.4 \\
Splenius L & 0.99 & 0.9 & 2.1 \\
Longissimus R & 0.88 & 3.1 & 5.4 \\
Longissimus L & 0.98 & 2.1 & 5.0 \\
Semi-spinalis capitis R & 0.96 & 2.6 & 5.0 \\
Semi-spinalis capitis L & 0.99 & 1.6 & 4.2 \\
Transverso spinalis R & 0.94 & 2.0 & 4.4 \\
Transverso spinalis L & 0.91 & 1.8 & 5.1 \\
Ventral muscles R & 0.88 & 3.8 & 7.5 \\
Ventral muscles L & 0.84 & 4.0 & 6.5 \\
Scalenus R & 0.87 & 3.9 & 6.8 \\
Scalenus L & 0.83 & 6.4 & 9.4 \\
Levator scapulae R & 0.86 & 3.9 & 9.9 \\
Levator scapulae L & 0.98 & 2.3 & 4.2 \\
Rhomboid R & 0.95 & 1.8 & 4.0 \\
Rhomboid L & 0.85 & 3.3 & 6.1 \\
Hyoid & 0.94 & 4.10 & 11.60 \\
\hline
\end{tabular}

dimensional reconstruction from MRI images. The DSPO method appeared useful to reduce the number of manual contours; however, it was sometimes difficult to find the boundary of a given muscle and the reconstruction of cervical muscles was still challenging and time-consuming due to the complicated cervical muscle structure. The mean time for a reconstruction was one hour. Once fully trained, two observers performed six cases to evaluate the reliability of the reconstruction method, and we also obtained in vivo specimen measurement data as a reference to see if the results was consistent with the MRI reconstructions. Because the reconstruction was conducted with manual contouring, the accuracy of the reconstruction depended on the proficiency of the observer after the learning curve and the quality of the MR images. This is a limit of the current method,
Figure 3. Result of six cases compared with the direct in vivo specimen measurements (left side).

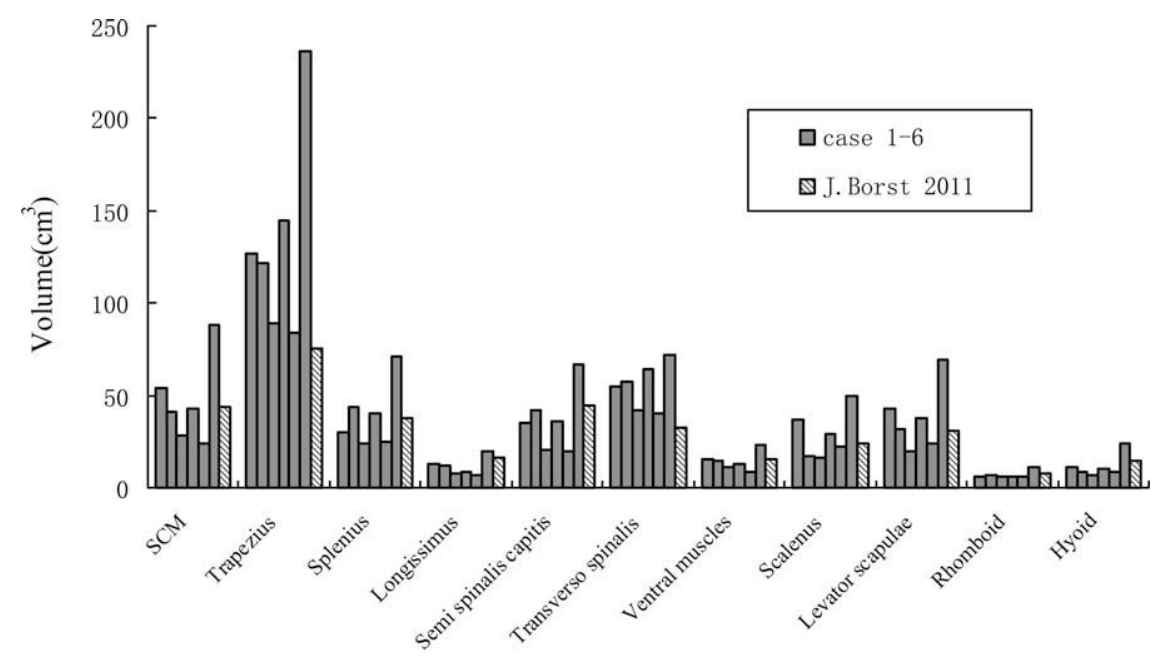

Muscle groups 

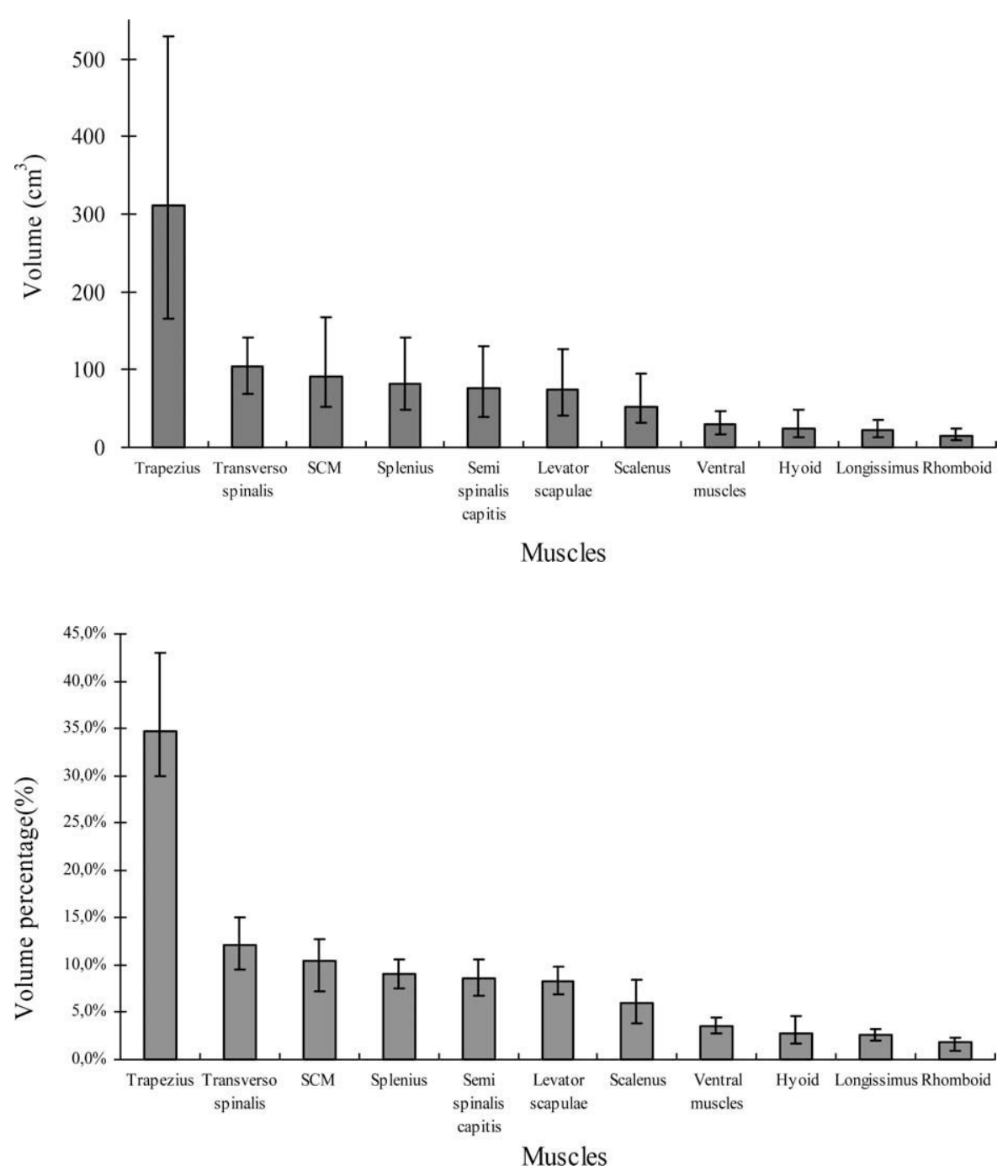

Figure 4. Mean volume and maxmin volume (between bars) of cervical muscles.
Figure 5. The volume proportion of cervical muscles.

Table 2

Case by Case Data for Volume of Individual Muscles as a Proportion of Total Cervical Muscle Volume (\%)

\begin{tabular}{|c|c|c|c|c|c|c|c|c|c|c|c|}
\hline Case no. & SCM & Trapezius & Splenius & Longissimus & $\begin{array}{c}\text { Semi- } \\
\text { spinalis } \\
\text { capitis }\end{array}$ & $\begin{array}{c}\text { Transverso } \\
\text { spinalis }\end{array}$ & $\begin{array}{l}\text { Ventral } \\
\text { muscles }\end{array}$ & Scalenus & $\begin{array}{l}\text { Levator } \\
\text { scapulae }\end{array}$ & Rhomboid & Hyoid \\
\hline 1 & 12.7 & 32.2 & 8.2 & 3.0 & 7.6 & 11.7 & 4.1 & 6.2 & 7.6 & 2.3 & 4.5 \\
\hline 2 & 9.2 & 37.7 & 8.6 & 2.9 & 7.8 & 12.8 & 3.1 & 6.1 & 6.9 & 1.9 & 2.9 \\
\hline 3 & 10.1 & 36.0 & 9.2 & 2.1 & 8.7 & 11.3 & 3.7 & 6.1 & 9.1 & 2.2 & 1.6 \\
\hline 4 & 7.7 & 43.0 & 7.5 & 2.3 & 6.8 & 10.6 & 3.4 & 5.6 & 8.9 & 2.0 & 2.3 \\
\hline 5 & 12.7 & 33.2 & 8.6 & 2.6 & 8.8 & 11.0 & 3.4 & 6.7 & 8.0 & 2.1 & 2.9 \\
\hline 6 & 9.7 & 32.7 & 10.6 & 2.7 & 10.6 & 11.2 & 3.4 & 5.5 & 8.9 & 1.7 & 2.8 \\
\hline 7 & 10.9 & 39.2 & 10.3 & 2.4 & 8.8 & 9.6 & 2.8 & 5.0 & 7.3 & 0.9 & 2.9 \\
\hline 8 & 7.2 & 35.0 & 10.1 & 3.0 & 10.3 & 12.5 & 3.9 & 6.3 & 7.5 & 1.4 & 2.8 \\
\hline 9 & 9.0 & 39.5 & 8.7 & 2.8 & 8.4 & 11.4 & 3.4 & 4.9 & 7.8 & 1.9 & 2.2 \\
\hline 10 & 12.1 & 35.8 & 8.7 & 2.8 & 9.1 & 11.1 & 3.4 & 3.8 & 8.0 & 1.8 & 3.4 \\
\hline 11 & 12.4 & 29.9 & 7.5 & 3.2 & 8.2 & 12.7 & 3.6 & 8.4 & 9.9 & 1.5 & 2.7 \\
\hline 12 & 10.2 & 31.8 & 10.4 & 2.9 & 9.9 & 14.0 & 3.7 & 4.5 & 8.7 & 1.8 & 2.1 \\
\hline 13 & 11.0 & 32.3 & 9.1 & 2.7 & 7.8 & 15.1 & 4.5 & 5.7 & 7.6 & 2.0 & 2.4 \\
\hline 14 & 10.3 & 32.8 & 9.7 & 2.1 & 8.5 & 14.6 & 3.1 & 7.0 & 8.2 & 1.3 & 2.4 \\
\hline 15 & 10.1 & 31.3 & 9.1 & 2.4 & 7.4 & 14.8 & 3.2 & 7.4 & 8.7 & 2.4 & 3.3 \\
\hline 16 & 12.0 & 31.8 & 10.2 & 2.4 & 9.3 & 10.2 & 3.3 & 6.8 & 9.1 & 1.5 & 3.5 \\
\hline Mean_P* & 10.5 & 34.6 & 9.1 & 2.6 & 8.6 & 12.2 & 3.5 & 6.0 & 8.3 & 1.8 & 2.8 \\
\hline Mean_Z* & 15.0 & 27.9 & 9.7 & 2.9 & 10.7 & 7.5 & 3.5 & 6.3 & 9.7 & non & 2.9 \\
\hline Min & 7.2 & 29.9 & 7.5 & 2.1 & 6.8 & 9.6 & 2.8 & 3.8 & 6.9 & 0.9 & 1.6 \\
\hline Max & 12.7 & 43.0 & 10.6 & 3.2 & 10.6 & 15.1 & 4.5 & 8.4 & 9.9 & 2.4 & 4.5 \\
\hline
\end{tabular}

*Mean_P: Mean value in the present study. Mean_Z: Mean value in the study done by Zheng et al (8). 
Figure 6. The maximum cross sectional area of cervical muscles.

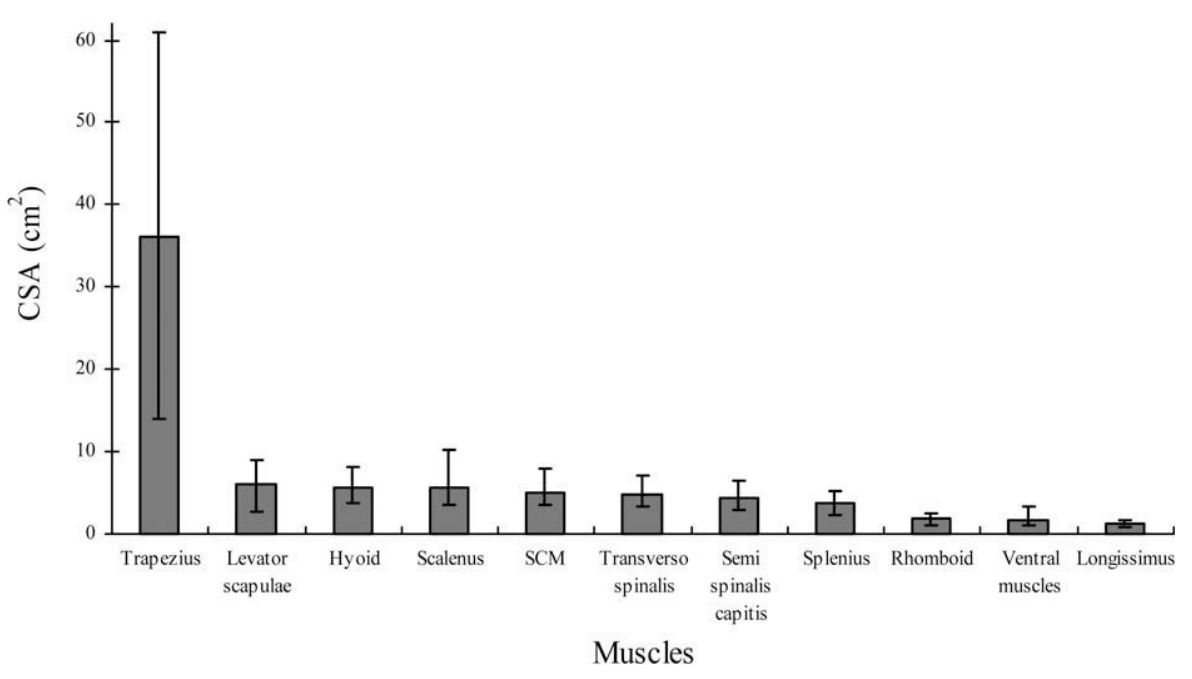

proportion study performed using MRI could quantify a muscle ratio under the corridor of normality while electromyography test cannot be conducted. As FE head-neck models are widely used in the vehicle safety area, and researchers are trying to find a way to scale the standard model to accommodate the large range of human anatomy, the results of the present work could provide reference data for $\mathrm{FE}$ model scaling.

Cervical muscle CSA has been previously studied in clinical and vehicle safety areas for whiplash associated disorders (WAD) $(17,18)$. In study by Matsumoto et al (17), based on 60 healthy volunteers, the maximum CSAs of semispinalis cervicis, semispinalis capitis, splenius capitis, and multifidus (vertebra level from C3 to C6) were $357.1 \pm 88.8$ (C5-C6), $483.8 \pm$ 172.5 (C3-C4), $503.9 \pm 147.2$ (C5-C6), and $261.0 \pm$ $75.2 \mathrm{~mm}^{2}$ (C5-C6), respectively (one side). Elliott et al $(5,18)$ measured 136 subjects for the relative CSA of cervical extensor musculature from $\mathrm{C} 3$ to $\mathrm{C} 7$ level. Because of the different definition of the muscle groups, the results of these studies were not able to be compared with present study. However, the vertebral level where the maximum CSA was located in accordance with the anatomical structures of the cervical muscles and the order of magnitude of maximum CSA was comparable to the total MRI results of the present study.

The limitation of the present study is the low number of the subjects. However this study has provided results which could be used as reference data for clinical evaluation and biomechanical model development.

Table 3

Location and Mean Value of Maximum CSA of Cervical Muscle

\begin{tabular}{|c|c|c|c|c|c|c|c|c|c|c|c|}
\hline $\begin{array}{l}\text { Muscle } \\
\text { group }\end{array}$ & SCM & Trapezius & Splenius & Longissimus & $\begin{array}{c}\text { Semi- } \\
\text { spinalis } \\
\text { capitis }\end{array}$ & $\begin{array}{c}\text { Transverso } \\
\text { spinalis }\end{array}$ & $\begin{array}{l}\text { Ventral } \\
\text { muscles }\end{array}$ & Scalenus & $\begin{array}{l}\text { Levator } \\
\text { scapulae }\end{array}$ & Rhomboid & Hyoid \\
\hline Location & $\mathrm{C} 6-\mathrm{C} 7$ & C6-C7 & C2-C3C6-C7 & $\mathrm{C} 2-\mathrm{C} 7$ & $\mathrm{C} 1-\mathrm{C} 2$ & C6-C7 & $\mathrm{C} 1-\mathrm{C} 2 \mathrm{C} 6-\mathrm{C} 7$ & C6-C7 & C6-C7 & C6-C7 & $\mathrm{C} 4-\mathrm{C} 7$ \\
\hline $\begin{array}{l}\text { Mean } \\
\quad \text { value } \\
\left(\mathrm{mm}^{2}\right)\end{array}$ & 498.7 & 3601.1 & 383.5 & 116.3 & 446.6 & 483.3 & 163.8 & 564.1 & 601.5 & 190.5 & 567.7 \\
\hline
\end{tabular}




\section{REFERENCES}

1. Jull GA, O'Leary SP, Falla DL. Clinical assessment of the deep cervical flexor muscles: the craniocervical flexion test. J Manipulative Physiol Ther 2008;31:525-533.

2. Kilgour AH, Subedi D, Gray CD, et al. Design and validation of a novel method to measure cross-sectional area of neck muscles included during routine MR brain volume imaging. PLoS One 2012;7:e34444.

3. Tracy BL, Ivey FM, Jeffrey Metter E, Fleg JL, Siegel EL, Hurley $\mathrm{BF}$. A more efficient magnetic resonance imaging-based strategy for measuring quadriceps muscle volume. Med Sci Sports Exerc 2003;35:425-433.

4. Kim S, Lee H, Adams R, Kwon M, Lim BK, Kim H. Is activityrelated change in cervical muscle thickness related to proprioceptive sensitivity at neck? World Physical Therap, Amsterdam, 2011.97(S1). No. RR-PO-206-26-Tue.

5. Elliott J, Jull G, Noteboom JT, Galloway G. MRI study of the cross-sectional area for the cervical extensor musculature in patients with persistent whiplash associated disorders (WAD). Man Ther 2008;13:258-265.

6. Hedenstierna S. 3D Finite element modeling of cervical musculature and its effect on neck injury prevention. Doctor Thesis. Stockholm: Royal Institute of Technology; 2008. 60 p.

7. Osth J.Active muscle responses in a finite element human body model. Doctor Thesis. Chalmers University of Technology; 2010. 22 p.

8. Zheng L, Siegmund G, Ozyigit G, Vasavada A. Sex-specific prediction of neck muscle volumes. J Biomech 2013;46:899-904.

9. Borst J, Forbes PA, Happee R. Veeger DH. Muscle parameters for musculoskeletal modelling of the human neck. Clin Biomech 2011;26:343-351.
10. Jolivet E, Daguet E, Pomero V, Bonneau D, Laredo JD, Skalli W. Volumic patient-specific reconstruction of muscular system based on a reduced dataset of medical images. Comput Methods Biomech Biomed Engin 2008;11: 281-290.

11. Jolivet E, Daguetb E, Bousson V, Bergot C, Skalli W, Laredo JD. Variability of hip muscle volume determined by computed tomography. IRBM 2009;30:14-19.

12. Laville A.Modélisation géométrique et mécanique du complexe musculo-squelettique du rachis cervical sous facteur de charge. Doctor Thesis, Arts et Métiers ParisTech; 2009. 162 p.

13. Shrout PE, Fleiss FL. Intraclass correlations: uses in assessing rater reliability. Psychol Bull 1979;86:420-428.

14. Shrout PE. Measurement reliability and agreement in psychiatry. Stat Methods Med Res 1998;7:301-317.

15. Fleiss JL, Levin B, Paik MC. Statistical methods for rates and proportions. New York: John Wiley and Sons; 2003. 800 p.

16. Zheng L.Sex differences in human neck musculoskeletal biomechanics and modeling. Doctor Thesis. Washington State University; 2011. 180 p.

17. Matsumoto M, Ichihara D, Okada E, et al. Cross-sectional area of the posterior extensor muscles of the cervical spine in whiplash injury patients versus healthy volunteers-10 year follow-up MR study. Injury 2012;43:912-916.

18. Elliott JM, Jull GA, Noteboom JT, Durbridge GL, Gibbon WW. Magnetic resonance imaging study of cross-sectional area of the cervical extensor musculature in an asymptomatic cohort. Clin Anat 2007;20:35-40. 